\title{
Q\&A: Choon Fong Shih
}

On 23 September, King Abdullah of Saudi Arabia will open the new King Abdullah University of Science and Technology (KAUST), an endeavour to build an internationally competitive university from scratch. Officials say they have recruited some 70 professors, mainly in chemistry, physics, mathematics and engineering; fewer than $10 \%$ of them, however, are women. KAUST has furnished laboratories with cutting-edge equipment, including a 222-teraflop Shaheen supercomputer from IBM. But questions remain over whether KAUST can become a true player on the international stage and whether academic freedom can flourish there. Nature spoke to Choon Fong Shih, its first president.

\section{Why did you take the job?}

King Abdullah's vision captured my imagination. The king spoke of KAUST as rekindling the Islamic spirit of learning and scientific inquiry, of inspiring a new age of scientific achievement for the region.

In fact, the king spoke of KAUST as the new House of Wisdom. The Islamic House of Wisdom was a centre of learning; it drew the very best minds from the known world to discover knowledge, to share knowledge and to apply knowledge.

\section{Why did the king decide to invest so much in KAUST?}

He sees KAUST as a catalyst to bring about a new age of scientific achievement.

Western countries have invested in their universities for centuries. Today we see the fruits of that investment. The investment in higher education and in research is a recent investment for this part of the world, and I believe in time we will see the fruit and the benefit.

\section{What are your key aims for the university?}

I see KAUST as a new paradigm in academia, advancing the frontiers of science, harnessing science and technology to address some of the global challenges of our time. So that means discovery and the creation of results, and also applying those results to the problems that face humanity.

We want to stand with the leading research universities around the world. In a generation or so, we will stand among them.

\section{How will you quantify success?}

We hope in ten years that our publications per academic will be equal to those of the very best research universities. We are looking at the metrics, both qualitative and quantitative, to be comparable to the top research universities around the world.

But, more than that, we will encourage partnerships with major corporations.

\section{How has the world financial downturn affected KAUST? Do you still have a \$10-billion endowment?}

The endowment is in good hands; it is intact and we are doing well. Besides the endowment, we have other sources

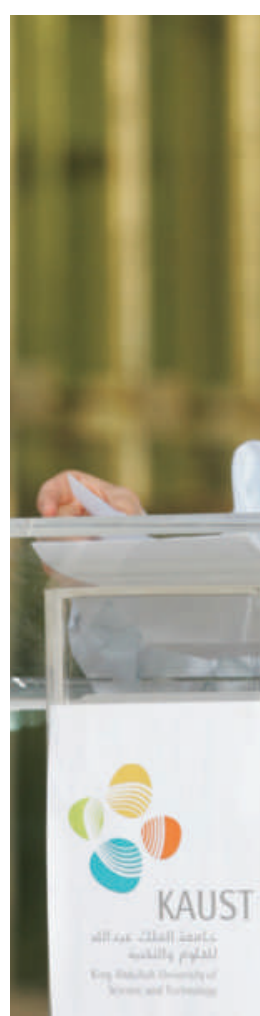

of revenue to support KAUST: we have sponsored research that brings in revenue from working with companies, we are sending proposals to government funding agencies and other funding agencies around the world, and we have benefactors who are contributing because KAUST has captured the imagination. We also have tuition income.

We see this as an opportunity. We work harder to recruit the best academics from regions affected by the economic downturn.

\section{Will home-grown talent eventually form the bulk of the faculty?}

KAUST recruits by global standards. We will not be taking our own students as faculty members because they graduated from KAUST. They will be subject to the same standards we apply to candidates around the world.

I believe that our $\mathrm{PhD}$ graduates will be very competitive for faculty positions at KAUST and around the world.

\section{How do you encourage women to come to KAUST? Aren't they put off coming to Saudi Arabia because of the stiff restrictions on life outside the university?}

We have many women on campus. This is a research environment. Our people here - men and women enjoy the same opportunities, the same resources, as they would find in America, in Europe and in Asia.

What research areas are you tackling? Will you eventually work in politically difficult fields, such as nuclear research?

We have a very active programme in renewable energy. We have a programme to turn sea water into clean, potable water. We are doing plant biology so we can grow plants in arid conditions and green the desert land into arable land.

We are looking at some of the most pressing challenges of our time. There is no shortage of exciting problems. Our plate is full.

How long do you intend to stay at KAUST? I spent 30 years in the East, I spent 30 years in North America, and with some luck I hope to spend 30 years at the confluence of East and West. Interview by Daniel Cressey 